\title{
Editorial
}

\section{Energy Production Systems}

\author{
Ali Elkamel 1,2 \\ 1 Department of Chemical Engineering, University of Waterloo, 200 University Avenue West, Waterloo, ON \\ N2L 3G1, Canada; aelkamel@uwaterloo.ca \\ 2 The Petroleum Institute, Part of Khalifa University of Science \& Technology, P.O. Box 2533, \\ Abu Dhabi 2533, UAE
}

Received: 12 July 2018; Accepted: 12 September 2018; Published: 20 September 2018

check for updates

This Special Issue aims to present solutions that effectively account for sustainability and lower greenhouse gas emissions, while meeting growing energy demands. The quest for pollution prevention and increased pressure and demand for environmentally sustainable processes and products have been creating new rules in the process industry. Sustainability is defined as "economic development that meets the needs of the present generation without compromising the ability of future generations to meet their own needs". The aim of this Special Issue is to present new solutions to one of the grand challenges of this century: supplying energy to a growing population in an environmentally and economically sustainable way. Since no single technology can meet this ultimate energy challenge of the future on its own, promising solutions are based on energy system approaches that can provide insight and data on how viable an energy production pathway can be. A diverse number of energy sources can be taken into account, including biomass, hydroelectric, wind, solar, natural gas, coal, and nuclear energy. The papers in this Special Issue present optimal solutions to effectively account for sustainability and lower greenhouse gas emissions, while meeting growing energy demands. The papers provide reliable and innovative ideas, applications, and tested implementations of energy systems that deal with a multiregion, multitechnology decision framework that is based upon a bottom-up view of industrial activities and a top-down view of energy and other product demands.

The first paper, by Al-Sobhi et al. [1], sets the stage for the remainder of the Issue and provides a comprehensive framework for the synthesis and design of natural gas utilization networks considering $\mathrm{CO}_{2}$ emissions. Since a multitude of potential diversification and conversion options are available for the utilization of natural gas resources, as well as several design configurations and technology choices that exist for the conversion of natural gas to value-added products, the paper presents a novel and detailed mathematical model that is able to select an optimal configuration and operating mode among the various options available and at the same timing maximizing profits and minimizing $\mathrm{CO}_{2}$ emissions.

The next paper, by Yu et al. [2], considers large-scale wind farms that are included in cogeneration systems and recommends the utilization of electrical energy storage and thermal energy auxiliaries in order to reduce the large amount of wind energy that may have to be wasted. Storage systems investigated by the authors included pumped hydro storage (PHS), compressed air energy storage (CAES), hydrogen-based energy storage (HES), heat storage (HS), electric boilers (EB), and heat pumps (HP). The paper proposes a general evaluation method to compare the performance of these different approaches for promoting wind power integration.

Paper three, by Noussan and Nastasi [3], makes use of an emerging topic in the area of energy systems - big data analytics - and provides an insightful analysis on building heating systems. A dataset of almost 2.9 million heating systems was analyzed with the aim of describing the features of current heating systems in households, offices, and public buildings. Several aspects are considered, including the type of heating systems, their thermal power, fuels, age, and nominal and measured 
efficiency. The paper represents an important contribution for adopting energy efficiency measures and implementing local policies for energy planning.

Paper four, by Kang et al. [4], deals with an important aspect that is often neglected in the area of energy production systems, and that is of the security aspects of power systems. In this respect, the paper focuses on the problem of how to maximize power system static security in terms of branch loading and voltage level under normal operation and even the most critical single-line contingency conditions. The paper proposes a hybrid approach to find out the optimal locations and settings of two classical types of flexible AC transmission system devices for solving this problem. The approach has been demonstrated on the IEEE 6-bus and modified IEEE 14-bus test systems.

The next paper of the Special Issue, by Olave-Rojas et al. [5], presents an optimization framework for investments in complex renewable energy systems, with a focus on the appropriate design and sizing of power systems that exploit the benefits of incorporating storage facilities along with renewable generation of power. The approach is illustrated on a real case study in the central region of Chile and shows the potential of the developed tool for aiding long-term investment planning.

In a deviation from the above papers, the paper by Jin et al. [6] presents an analysis of Greenhouse Gas Emission (GHG) reduction employing a $\mathrm{CO}_{2}$ transportation network model. The paper proposes optimal pipeline transportation networks for large-scale CCS projects. The objective of the proposed model is to minimize the total investment cost of CCS, including pipeline capital costs, operation costs, and facility costs. The paper analyzes a number of scenarios of Korean CCS projects.

The adaptation of renewable energy employing concentrated solar power plants is subject to sensitive variations of the steam production profile and external disturbances. The paper by Iannino et al. [7] proposes advanced control techniques that ensure system stability and suitable performance criteria. The paper presents the design of a multiobjective $\mathrm{H}_{\infty}$ robust controller and applies it to the power control of a concentrated solar power plant consisting of two turbines, a gear, and a generator. The simulations results show that the proposed controller achieves better robustness and performance compared to the existing, more traditional control strategies.

The papers by Fowler and coworkers of this Special Issue (Mukherjee et al. [8] and Maroufmashat and Fowler [9]) deal with an important concept in energy systems: power to gas. This is a promising option for storing intermittent renewables, nuclear baseload power, and distributed energy and is a novel concept for the transition to increased renewable content of current fuels. The paper by Mukherjee et al. [8] presents a stochastic programming approach for the planning and operation of a power-to-gas energy hub with multiple energy recovery pathways. The paper focuses on assessing the benefits of power-to-gas while accounting for uncertainty in several key parameters that could influence the operation of the energy system. The paper by Maroufmashat and Fowler [9], on the other hand, presents a review and detailed comparisons of different power-to-gas "pathways", including power to hydrogen, power to natural gas end-users, power to renewable content in petroleum fuel, power to power, seasonal energy storage to electricity, power to zero-emission transportation, power to seasonal storage for transportation, power to microgrid, power to renewable natural gas (RNG) to pipeline ("methanation"), and power to renewable natural gas (RNG) to seasonal storage. The comparison includes the efficiency and benefits of each pathway from technical points of view. Moreover, the pathways are also discussed as an energy policy option that can be implemented in a transition towards a lower carbon economy.

In a departure from the above papers, the paper by Ibarra et al. [10] presents an overview of real-time simulation and its applicability to smart grid attainment. The paper gives also an overview of the evolution of real-time simulators in the industrial and academic background and its current challenges.

The next paper of this Special Issue (by Gabbar et al. [11]) focuses on a direct current (DC) thermal plasma design and utilization for the conversion of low-density polyethylene to diesel oil through the thermal cracking process called pyrolysis. This is an important contribution given the exponential increase of plastic production, reaching around 100 million tonnes of waste plastics annually, and 
more significantly given that the thermal plasma process is able to meet thermal requirements without fuel emissions like gas burners. The paper illustrates an experimental setup that consists of a vacuum pump, closed system vessel, direct current (DC) plasma circuit, and a k-type thermocouple. The hydrocarbon products are condensed to diesel oil and analyzed using flame ionization detector (FID) gas chromatography. The analysis shows that the direct current (DC) thermal plasma achieves around $60 \mathrm{wt}$ \% diesel range oil and $40 \mathrm{wt}$. \% gaseous products and minimal tar production.

The paper by Shi et al. [12] deals with electricity gas and heat subsystems in local-area energy systems integration (ESI) as a way to alleviate environmental pollution and improve the efficient use of energy. The paper proposes a generalized energy flow (GEF) analysis method. The method employs a hybrid strategy that combines homotopy and the Newton-Raphson algorithm to resolve the nonlinear equations of GEF. The Jacobi matrix employed in the approach and which reflects the coupling relationship of multienergy systems was derived considering the grid-connected mode and island modes of the power system in the ESI. The simulation results showed that the proposed algorithm could converge to numerical solutions at a reasonable speed while the power system of ESI runs in grid-connected or island modes. The methodology was illustrated in several practical cases.

The next paper by Alsharif [13] is based on the characteristics of South Korean solar radiation exposure and focuses on the techno-economic evaluation of deployment and operation of two solar-powered global systems for mobile communication base stations (GSM BS 2/2/2 and GSM BS $4 / 4 / 4)$. The paper presents the optimum criteria as well as economic and technical feasibility for the base stations and analyzes the initial capital, replacement, operations, maintenance, and total net present costs.

The paper by Chebeir [14] of the Special Issue addresses the long-term planning problem of the shale gas supply chain under uncertainty through a two-stage stochastic programming approach. Inherent uncertainty in final products' prices, such as natural gas and natural gas liquids (NGL), is treated through the utilization of a scenario-based method. The model is shown to generate a realistic supply chain network configuration as well as scheduling of different operations throughout the planning horizon of a shale gas development project.

The next paper, by Choi et al. [15], focuses on a different energy harvesting scheme: wearable biomechanical energy. Energy harvesting technology can guarantee an increased leisure and safety for humans where stable electrical supply is not possible. The paper starts by reviewing energy harvesting technologies that harvest biomechanical energy from human motion and then classifies them based on the principle of kinetic energy harvesting: piezoelectric, triboelectric, and electromagnetic energy harvesting.

Finally, the paper by Obaid et al. [16] compares steady-state and non-steady-state emissions under start-up and shut-down operations of several energy production methods, as well as other chemical systems, and develops trends for the various systems. The findings of this research are aimed to help air permit applicants to effectively allocate their resources when assessing emissions related to non-steady-state operations. This is especially important when emissions under start-up and shut-down operations have the potential to exceed enforceable emission limits. This will help in preventing the emissions from adversely impacting public health and the environment.

Coming to the end of this preface, the guest editor would like to thank all the authors for their submissions of such high-quality manuscripts and the many colleagues who participated in the review process.

Finally, we wish you a fulfilling journey in savoring the breadth of the intellectual offering that this Special Issue offers.

Conflicts of Interest: The authors declare no conflicts of interest 


\section{References}

1. Al-Sobhi, S.; Elkamel, A.; Erenay, F.; Shaik, M. Simulation-Optimization Framework for Synthesis and Design of Natural Gas Downstream Utilization Networks. Energies 2018, 11, 362. [CrossRef]

2. Yu, Y.; Chen, H.; Chen, L. Comparative Study of Electric Energy Storages and Thermal Energy Auxiliaries for Improving Wind Power Integration in the Cogeneration System. Energies 2018, 11, 263. [CrossRef]

3. Noussan, M.; Nastasi, B. Data Analysis of Heating Systems for Buildings-A Tool for Energy Planning, Policies and Systems Simulation. Energies 2018, 11, 233. [CrossRef]

4. Kang, T.; Yao, J.; Duong, T.; Yang, S.; Zhu, X. A Hybrid Approach for Power System Security Enhancement via Optimal Installation of Flexible AC Transmission System (FACTS) Devices. Energies 2017, 10, 1305. [CrossRef]

5. Olave-Rojas, D.; Álvarez-Miranda, E.; Rodríguez, A.; Tenreiro, C. An Optimization Framework for Investment Evaluation of Complex Renewable Energy Systems. Energies 2017, 10, 1062. [CrossRef]

6. Jin, S.; Bai, L.; Kim, J.; Jeong, S.; Kim, K. Analysis of GHG Emission Reduction in South Korea Using a CO2 Transportation Network Optimization Model. Energies 2017, 10, 1027. [CrossRef]

7. Iannino, V.; Colla, V.; Innocenti, M.; Signorini, A. Design of a $\mathrm{H} \infty$ Robust Controller with $\mu$-Analysis for Steam Turbine Power Generation Applications. Energies 2017, 10, 1026. [CrossRef]

8. Mukherjee, U.; Maroufmashat, A.; Narayan, A.; Elkamel, A.; Fowler, M. A Stochastic Programming Approach for the Planning and Operation of a Power to Gas Energy Hub with Multiple Energy Recovery Pathways. Energies 2017, 10, 868. [CrossRef]

9. Maroufmashat, A.; Fowler, M. Transition of Future Energy System Infrastructure; through Power-to-Gas Pathways. Energies 2017, 10, 1089. [CrossRef]

10. Ibarra, L.; Rosales, A.; Ponce, P.; Molina, A.; Ayyanar, R. Overview of Real-Time Simulation as a Supporting Effort to Smart-Grid Attainment. Energies 2017, 10, 817. [CrossRef]

11. Gabbar, H.; Aboughaly, M.; Stoute, C. DC Thermal Plasma Design and Utilization for the Low Density Polyethylene to Diesel Oil Pyrolysis Reaction. Energies 2017, 10, 784. [CrossRef]

12. Shi, J.; Wang, L.; Wang, Y.; Zhang, J. Generalized Energy Flow Analysis Considering Electricity Gas and Heat Subsystems in Local-Area Energy Systems Integration. Energies 2017, 10, 514. [CrossRef]

13. Alsharif, M. Techno-Economic Evaluation of a Stand-Alone Power System Based on Solar Power/Batteries for Global System for Mobile Communications Base Stations. Energies 2017, 10, 392. [CrossRef]

14. Chebeir, J.; Geraili, A.; Romagnoli, J. Development of Shale Gas Supply Chain Network under Market Uncertainties. Energies 2017, 10, 246. [CrossRef]

15. Choi, Y.; Lee, M.; Jeon, Y. Wearable Biomechanical Energy Harvesting Technologies. Energies 2017, 10, 1483. [CrossRef]

16. Obaid, J.; Ramadan, A.; Elkamel, A.; Anderson, W. Comparing Non-Steady State Emissions under Start-Up and Shut-Down Operating Conditions with Steady State Emissions for Several Industrial Sectors: A Literature Review. Energies 2017, 10, 179. [CrossRef]

(C) 2018 by the author. Licensee MDPI, Basel, Switzerland. This article is an open access article distributed under the terms and conditions of the Creative Commons Attribution (CC BY) license (http://creativecommons.org/licenses/by/4.0/). 